\title{
Deliberate sulphonylurea poisoning mimicking hyperinsulinaemia of infancy
}

Louise Owen, Matthew Ellis, Julian Shield

\begin{abstract}
A 6 month old child presenting with seizures was found to be hypoglycaemic secondary to hyperinsulinism. A family history of type II diabetes prompted estimation of sulphonylurea in the baby's blood, which was found to be high. A multidisciplinary case conference concluded that the sulphonylurea ingestion was likely to be the result of Munchausen syndrome by proxy. When investigating hypoglycaemia of infancy this possibility should be considered.

(Arch Dis Child 2000;82:392-393)
\end{abstract}

Keywords: Munchausen syndrome by proxy; diabetes; sulphonylurea

\section{Case report}

A 6 month old child presented to the accident and emergency department following a generalised seizure. The patient was apyrexial, poorly perfused, and responding only to pain. There was no report of choking, apnoea, or cyanosis, and no significant past medical history. On arrival at hospital the baby was resuscitated and underwent a septic screen, which was negative, and a urine toxicology screen which did not detect benzodiazepines, amphetamines, cocaine, methadone, or opiates. Blood glucose was $6.0 \mathrm{mmol} / \mathrm{l}(2.6-7.0$ $\mathrm{mmol} / \mathrm{l})$; examination was unremarkable. The child remained unresponsive for five hours after admission, before returning to normal consciousness. No further seizure activity was reported.

Five days later the child presented again with a history of a seizure. On arrival the child was conscious and alert, but capillary blood glucose was $1.3 \mathrm{mmol} / \mathrm{l}$. Plasma ammonia and lactate were normal, urinary ketones were negative. Dextrose $10 \%$ was administered, providing more than $10 \mathrm{mg} / \mathrm{kg} / \mathrm{min}$ glucose. Despite this, the blood glucose repeatedly fell below 2.5 $\mathrm{mmol} / \mathrm{l}$, and further dextrose boluses were needed over the next 24 hours.

An initial insulin level was $428 \mathrm{pmol} / \mathrm{l}$, inappropriately high for the original blood glucose of $1.3 \mathrm{mmol} / 1$, and C peptide was $5.396 \mathrm{nmol} / 1$, suggesting endogenous hyperinsulinism. A full metabolic screen, prolonged fast, glucose tolerance test, and computed tomography of the pancreas revealed no abnormalities. The child had no further hypoglycaemic events.

Questioning on the ward the day after admission revealed that the maternal grandmother and great grandmother had type II diabetes mellitus, controlled with oral hypoglycaemic agents. Sulphonylurea concentrations were therefore requested on the blood samples from the second admission and were detected at a level of $806 \mu \mathrm{g} / \mathrm{l}$. The assay was unable to identify the precise type of sulphonylurea. Unfortunately lack of stored blood from the first admission precluded a retrospective assay.

A multidisciplinary case conference attended by representatives from social services, police, and health workers (community paediatrician and health visitors) revealed complex problems in coping mechanisms, as well as a history of violence, and physical and sexual abuse, in several family members. It was disclosed that the mother's first child had been removed from her care, aged 3, owing to emotional, physical, and sexual abuse. Both the mother and her then partner were named as perpetrators. The case conference convened on the present occasion recommended foster care pending further police investigation of presumed Munchausen syndrome by proxy.

\section{Discussion}

The differential diagnosis in cases of infant hypoglycaemia includes endocrine deficiencies, inborn errors of metabolism, and hyperinsulinism. However, sulphonylurea ingestion is not commonly considered. Accidental sulphonylurea ingestion is seen in young children, ${ }^{1}$ and cases of factitious hypoglycaemia have been reported, following intentional sulphonylurea ingestion by adults. ${ }^{2}$ However, deliberate administration of oral hypoglycaemic agents has not previously been described in infancy. The sulphonylurea level of $806 \mu \mathrm{g} / 1$ is extremely high; the usual therapeutic range in adults is $5-200 \mu \mathrm{g} / 1$.

There have been cases of prolonged neurological sequelae after sulphonylurea ingestion, ${ }^{3}$ despite correction of the blood glucose, with hemiparesis, agitation, and confusion persisting for up to 48 hours post ingestion. This raises the possibility that the patient's first admission might also have been owing to sulphonylurea ingestion. Her blood glucose on admission was normal but her neurological status remained depressed for several hours.

The standard investigations for hypoglycaemia in infancy do not include an estimation of sulphonylurea concentrations. The initial finding in this child appeared consistent with endogenous hyperinsulinaemia. When investigating hypoglycaemia of infancy we suggest that a history of potentially available sources of oral hypoglycaemic agents should be elicited from carers. If such a history is obtained, estimation of sulphonylurea concentrations should be undertaken. 
The authors acknowledge the assistance of Dr D Teale, Supraregional Peptide Laboratory, Royal Surrey County Hospital, Guildford.

1 Spiller HA, Villalobos D, Krenzelok EP, et al. Prospective multicenter study of sulfonylurea ingestion in children. $\mathcal{F}$ Pediatr 1997;131:141-6.
2 Sener A, Gillet C, Verhelst J, DeBeock K, Mahler C, Maliaisse WJ. Factitious hypoglycaemia documented by a modified assay for the measurement of plasma sulphonylurea. Diabet Med 1995;12:433-5.

3 Spiller HA, Schroeder SL, Ching DSY. Hemiparesis and altered mental status in a child after glyburide ingestion. $f$ Emerg Med 1998;16:433-5.

\section{FETAL AND NEONATAL EDITION May 2000 issue}

The following articles-being published in the May 2000 issue of the Fetal and Neonatal edition of the Archives of Disease in Childhood - may be of general interest to paediatricians.

\section{CONTROVERSY}

Antenatal treatment of a mother bearing the fetus with congenital adrenal hyperplasia

$C G D$ Brook

\section{ORIGINAL ARTICLES}

Antenatal and perinatal predictors of infant mortality in rural Malawi $M$ Vaahtara, $T$ Kulmala, $M$ Ndekha, A-M Koivisto, $T$ Cullinan, $M-L$ Salin, $P$ Ashorn

Effects of gestation and birthweight on the growth and development of very low birthweight small for gestational age infants: a matched group comparison

T Gutbrod, D Wolke, B Soehne, B Ohrt, K Riegel 